\title{
Síndrome de Guillain Barré Recurrente: Reporte de caso
}

\author{
Guillain Barré Syndrome Recurrent: Case report
}

\author{
Melida Galeas Oliva*, Fabiola Carolina Ramos
}

\section{RESUMEN}

El síndrome de Guillain-Barré (SGB) o polirradiculoneuritis aguda es una enfermedad autoinmune, desencadenada por una infección viral o bacteriana, su incidencia es de 1.7/100000, únicamente el 3\% puede recaer en los años subsiguientes. Es una patología poco frecuente y menos frecuente aún son los casos recurrentes, por lo que realizamos una revisión de su epidemiología, cuadro clínico, criterios diagnósticos y su manejo. Se trata de un paciente masculino de 9 años de edad, que el 13 de octubre de 2008 al primer año de edad fue ingresado durante 1 mes al Instituto Hondureño de Seguridad Social (IHSS) con cuadro de parálisis flácida ascendente progresiva (Síndrome de Guillain Barré), recibió manejo con inmunoglobulina cuya dosis y otros datos sobre su tratamiento, exámenes o estudios realizados se desconocen. La recuperación completa se dio aproximadamente a los 6 meses posteriores al inicio de los síntomas. Sin embargo reingresa el 12 de noviembre de 2014 en IHSS con diagnóstico de Parálisis Flácida ascendente recurrente (segundo episodio), sin recuperación completa ya que presentó secuelas en miembros inferiores. Se le realizó Electromiografía con datos compatibles con polirradiculopatía motora desmielinizante simétrica. En marzo de este año (2017) se presenta con igual sintomatología por lo que se ingresa como síndrome de Guillain barré recurrente (tercer episodio).

\section{PALABRAS CLAVE}

Síndrome Guillain Barré, Reporte de caso, Recurrente.

\footnotetext{
*Médico Residente. 3er año, Postgrado Pediatría, UNAH-VS. **Médico Residente. 1er año, Postgrado Pediatría, UNAH-VS. Dirigir correspondencia a fabiolaramos216@gmail.com

Recibido: 12 de Diciembre 2017 Aprobado: 5 de Marzo 2018
}

\section{ABSTRACT}

Guillain-Barré syndrome or acute polyradiculoneuritis is an autoimmune disease, triggered by a viral or bacterial infection, its incidence is $1.7 / 100000$, only $3 \%$ may relapse in subsequent years. It is a rare pathology and less frequent are still recurrent cases, so we perform a review of its epidemiology, clinical picture, diagnostic criteria and its management. This is a 1-year-old male patient, who on October 13, 2008 was admitted for 1 month to the Honduran Institute of Social Security (IHSS) with progressive ascending flaccid paralysis (Guillain Barré Syndrome), received management with immunoglobulin whose dose and other information about its treatment, tests or studies are unknown. Complete recovery occurred approximately 6 months after the onset of symptoms. However, she re-enrolled on November 12, 2014 at IHSS with a diagnosis of recurrent ascending flaccid paralysis (second episode), without complete recovery since she had sequelae in lower limbs. Electromyography was performed with data compatible with symmetric demyelinating motor polyradiculopathy. In March of this year (2017) is presented with the same symptomatology for what is entered as recurrent Guillain Barré syndrome (third episode).

\section{KEY WORDS}

Guillain Barré Syndrome, report of case, recurrent.

\section{INTRODUCCIÓN}

El síndrome de Guillain-Barré o polirradiculoneuritis aguda es una enfermedad autoinmune, desencadenada por una infección viral o bacteriana. Se caracteriza por una debilidad simétrica, rápidamente progresiva, de comienzo distal y avance proximal, a veces llegando a afectar la musculatura bulbar respiratoria, cursa con pérdida de reflejos 
osteotendinosos y con signos sensitivos leves o ausentes. En 2/3 de los casos han padecido una infección del tracto respiratorio o gastrointestinal 1-3 semanas antes. ${ }^{(1)}$ Es la causa más frecuente de parálisis neuromuscular aguda, con incidencia de 1,3 a 2 por 100.000 y su mortalidad alcanza el $5-15 \%$.(2)

Los gérmenes causantes más frecuentes, que hay que investigar son: 1. Campylobacter jejuni (26-41\% de los casos), asociado especialmente a formas axonales y al síndrome de Miller-Fisher, la cual se puede aislar en heces hasta varias semanas tras la terminación de la diarrea. 2. Citomegalovirus (10-22\%), particularmente frecuente en niñas. 3. Virus de Epstein-Barr (10\%). 4. Haemophilus influenzae (2-13\%), 5. Virus varicela-zoster. 6. Mycoplasma pneumoniae.

La incidencia del síndrome de Guillain Barré se reporta en 1.7/100000, dato que si extrapolamos a nuestro medio, podremos esperar unos 85 nuevos casos cada año de los cuales $10-23 \%$ ocuparán ventilador mecánico, 2-5\% morirán, 7-22\% tendrán algún tipo de secuela y 3-10\% tendrán recurrencia. ${ }^{(3)}$ Sólo un $10 \%$ de los pacientes presenta una recaída temprana de los síntomas en la primera semana después del tratamiento. El $3 \%$ puede recaer en los años subsiguientes. El $80 \%$ de los pacientes se recuperan completamente o presentan con déficit pequeños. Entre el 10 y el $15 \%$ quedarán con secuelas permanentes, el resto morirá a pesar de los cuidados intensivos. ${ }^{(1)}$

\section{CASO CLÍNICO}

Paciente masculino de 9 años de edad procedente de Naco, Cortés, ingresa al Hospital Mario Catarino Rivas (HMCR) el 2 de marzo de 2017, con historia de mialgias y artralgias de un día de evolución de moderada intensidad, atenuadas con analgésico (Ibuprofeno 1 tableta cada $8 \mathrm{hrs}$ ) y reposo, exacerbadas con actividad física, además se presenta con pérdida de la fuerza muscular en miembros inferiores de inicio súbito, mientras se encon- traba jugando en la escuela cayó de su propio eje de sustentación sin poder ponerse en pie nuevamente, la debilidad fue presentándose de manera ascendente, motivo por el cual acude a nuestro centro hospitalario. Refiere cuadro gastroentérico hace 4 días.

Al examen físico los hallazgos relevantes fueron pérdida de la fuerza muscular en miembros inferiores 2/5 y abolición de los reflejos osteotendinosos. Sensibilidad conservada. El análisis de líquido cefalorraquídeo (LCR) realizada 10 días posteriores al inicio de los síntomas reportó proteínas 100 $\mathrm{mg} / \mathrm{dl}$, glucosa: $50 \mathrm{mg} / \mathrm{dl}$ con glicemia de ese momento $86 \mathrm{mg} / \mathrm{dl}$, recuento de leucocitos $20 \mathrm{c} / \mathrm{mm}^{3}$, eritrocitos: 0 .

La electromiografía reportó: neuroconducción sensitiva normales, respuestas tardías: no se registraron respuestas $F$ en nervios pélvicos ni torácicos. En músculos paravertebrales lumbares: actividad de inserción levemente aumentada, actividad en reposo: ondas positivas y fibrilaciones en cantidad leve o moderada, patrón de interferencia incompleto, con características neuropatícas.

Paciente con antecedente de haber sufrido 2 episodios previos: el 13 de octubre de 2008 ingresó en el IHSS con cuadro de parálisis flácida ascendente progresiva diagnosticado como Síndrome de Guillain Barré, ingresado durante 1 mes, con el antecedente de haber recibido vacuna de SRP una semana antes del inicio de los síntomas, fue tratado con inmunoglobulina cuya dosis y otros datos sobre su tratamiento, exámenes o estudios realizados se desconocen. Afirmando que la recuperación completa se dio aproximadamente a los 6 meses posteriores al inicio de los síntomas con apoyo de fisioterapia. Reingresa el 12 de noviembre de 2014 en IHSS con diagnóstico de Parálisis Flácida ascendente y recurrente (segundo episodio), sin recuperación completa ya que presentó secuelas en miembros inferiores. Tratamiento recibido: inmunoglobulina $12 \mathrm{~g}$ IV cada día 
por 5 días y Oxcarbazepina 6 cc VO cada 12 horas. Se le realizó electromiografía que reportó: datos compatibles con polirradiculopatía motora de predominio desmielinizante simétrica. Inmunoserología: Citomegalovirus IgG positivo, IgM Negativo. Citoquímica de LCR: realizada el 17 de noviembre de 2014 con Proteínas 100 mg/dl, Glucosa: 60 mg/dl, Recuento de leucocitos: $16 \mathrm{c} / \mathrm{mm} 3$, Recuento de eritrocitos: 4, Recuento diferencial: del recuento total de leucocitos se observa el $100 \%$ de linfocitos.

\section{DISCUSIÓN}

La historia del síndrome de Guillain Barré se remonta al año de 1859 cuando Landry describió las características clínicas de una parálisis ascendente sin amiotrofia; Sin embargo fue hasta 1916 que Guillain Barré y Strohl describieron la existencia de un cuadro clínico caracterizado por una polirradiculoneuritis acompañada de disociación albuminocitológica en el examen del líquido cefalorraquídeo. En los 20 años subsecuentes, más de 30 casos fueron reportados en la literatura médica, siendo el mismo Guillain quien añadió 10 de estos casos en un artículo que publicó en 1936; desde entonces, la entidad se conoció bajo el epónimo de Síndrome de Guillain Barré. ${ }^{(4)}$

El síndrome de Guillain-Barré es una serie heterogénea de neuropatías periféricas mediadas inmunológicamente. El hallazgo común es la polirradiculopatía de evolución rápida, que se manifiesta posteriormente a un suceso disparador, que con frecuencia es un proceso infeccioso. Se manifiesta generalmente con una parálisis motora simétrica con o sin afectación sensorial y autonómica. Su diagnóstico se basa en el examen electrodiagnóstico ${ }^{(1)}$ análisis de LCR y evolución clínica.

El trastorno suele aparecer unos días o semanas después de que la persona haya tenido síntomas de infección viral respiratoria o intestinal, en algunas ocasiones, el embarazo, cirugías o las vacunas pueden desencadenar el síndrome. ${ }^{(2)}$ En el presente caso se relacionó el primer episodio a la aplicación de vacuna SRP, en el segundo y tercer episodio fueron precedidos por infección gastrointestinal.

Hasta este momento no existe cura alguna conocida para el Síndrome de Guillain-Barré, pues ciertas terapias se limitan a disminuir la gravedad de la enfermedad y acelerar la recuperación de los pacientes. Actualmente se defiende el uso del tratamiento combinado de inmunoglobulinas IV y plasmaféresis. En estos enfermos se impone cumplir las medidas generales prescritas para evitar y prevenir la aparición de complicaciones graves, que causan rápidamente la muerte. ${ }^{(5)}$ Cuando el Síndrome de Guillain-Barré va precedido de una infección viral, es posible que el virus cambie la naturaleza de las células en el sistema nervioso por lo que se reconoce a las células propias como extrañas, por lo que ciertas clases de linfocitos, atacan la mielina. Cuando esto ocurre los recubrimientos de mielina de los nervios periféricos son lesionados o quedan afectados, estos no pueden transmitir señales con eficiencia. A ello se debe el que los músculos comiencen a perder su capacidad de responder a las señales del cerebro, el cerebro también recibe menos señales sensoriales del resto del cuerpo, resultando en una incapacidad de sentir las texturas, el calor, el dolor y otras sensaciones. Como alternativa, el cerebro puede recibir señales inapropiadas que resultan en cosquilleo de la piel o en sensaciones dolorosas (parestesias e hiperestesias). ${ }^{(6)}$

Debido a que las señales que van hacia y vienen desde los brazos y las piernas han de recorrer largas distancias, son las más vulnerables a interrupción. Por tanto, las debilidades musculares y las sensaciones de cosquilleo aparecen inicialmente en manos y pies que progresan ascendentemente. ${ }^{(7)}$

Los criterios diagnósticos para SGB incluyen: debilidad progresiva, disminución o ausencia de reflejos de estiramiento muscular; debili- 
dad ascendente progresiva de musculatura pélvica y braquial. En 50\% llega a haber parálisis facial (uni o bilateral) y en algunos casos, debilidad oculomotora. Por tanto, el diagnóstico diferencial debe incluir los síndromes de debilidad flácida aguda. Criterios que cumplió a cabalidad nuestro paciente ya que su sintomatología fue en los tres episodios debilidad muscular progresiva, abolición de los reflejos osteotendinosos y conservación de la sensibilidad. De acuerdo con la localización topográfica se enlistan otras alternativas diagnósticas en el SGB.(1)

\section{Variantes del Síndrome de Guillain-Barré (sgb).}

En el SGB se incluyen las siguientes formas: Miller Fisher constituye un diagnóstico especial, ya que conforma aproximadamente $5 \%$ de los SGB. Inicialmente descrita como ataxia, oftalmoplejía y arreflexia. En la actualidad clínicamente prevalecen los datos de oftalmoplejía. La "ataxia" no es de origen cerebelosa, sino se debe a errores en la afluencia de propiocepción de las espirales o husos musculares y la información cinestésica de los receptores en las articulaciones.

Además de la oftalmoplejía, puede haber afectación de otros nervios craneales motores (formas incompletas o polineuritis craneales). Los estudios electrodiagnósticos demuestran afección axonal predominantemente sensitiva y mínima afección motora. El LCR, una semana después del inicio del cuadro, suele tener incremento de proteínas sin pleocitosis. La IRM no muestra alteración cerebral ni cerebelosa. En buena parte de los pacientes se detecta antecedente de infecciones en las vías aéreas superiores y/o por infecciones intestinales debido a $\mathrm{C}$. jejuni.

\section{Neuropatía Axonal Aguda Motora (AMAN)} indica una debilidad motora por una lesión de predominio axonal, y cuyo diagnóstico diferencial con poliomielitis, intoxicación por "tullidora", son problemas clínicos de amplio interés. El antecedente de C. jejuni se ha encontrado hasta en $76 \%$ en los casos de AMAN y la detección de anticuerpos antigangliósidos le confiere características de apoyo diagnóstico.

\section{Neuropatía Sensitivo-Motora Axonal} Aguda (AMSAN) es una mezcla de trastornos sensitivos además de los motores y sin ninguna otra característica específica diferencial. La forma "Pandisautonomía aguda" se caracteriza por falla aguda simpática y parasimpática incluyendo hipotensión ortostática, anhidrosis, ojos y boca secos, cambios en la frecuencia cardiaca, etc. Sin componente sensitivo o motor. La mitad de los pacientes tienen anticuerpos antirreceptores gangliónicos de acetilcolina. ${ }^{(8)}$

Las principales medidas terapéuticas incluyen plasmaféresis y la administración intravenosa de inmunoglobulinas. La plasmaféresis consiste en el intercambio de plasma por albúmina o por plasma fresco congelado, se extraen $50 \mathrm{~mL} / \mathrm{kg}$ en días alternos hasta completar 5 sesiones. ${ }^{(9)} \mathrm{Se}$ recomienda su uso precoz, principalmente en las 2 primeras semanas, en la fase de progresión del Síndrome de Guillain-Barré severo y en las recaídas; se plantea que mejora la evolución de la enfermedad, así como acorta el tiempo de ventilación mecánica. ${ }^{(10)}$

El uso de inmunoglobulinas intravenosas también ha demostrado efectividad tanto como en la plasmaféresis se aconseja al menos 5 dosis de $400 \mathrm{mg} / \mathrm{kg} / \mathrm{d}$ en las 2 primeras semanas. Las recaídas son más frecuentes que con la plasmaféresis, pero es tan efectiva como ella. ${ }^{(11)}$ Entre los objetivos de la rehabilitación en este padecimiento, están la prevención de complicaciones médicas asociadas, deformidades, contracturas y el mejoramiento de los arcos de movilidad comprometidos, así como incrementar la fuerza motora. Lograr la marcha y la independencia en las actividades de la vida cotidiana, disminuir la incapacidad física y acortar el período total de la enfermedad.(12) 
La recuperación es la regla en los que sobreviven, existiendo un período de "meseta" desde el pico de mayor intensidad hasta el inicio de la recuperación que va desde unas pocas horas hasta 45 días con media de 10 días y todo el proceso desde el inicio hasta la resolución final o estabilización dura entre 1 a 59 semanas con una media de nueve semanas. ${ }^{(13)}$

\section{REFERENCIAS BIBLIOGRÁFICAS}

1. Pascual SI, Protocolos Diagnóstico Terapéuticos de la AEP: Neurología Pediátrica. Servicio de Neurología Pediátrica. Hospital Infantil Universitario La Paz, Madrid, pag. 84-87.

2. Síndrome de Guillain-Barré", NINDS. Marzo 2007, National Institute of Neurological Disorders and Stroke. National Institutes of Health Bethesda, MD 208923.

3. Zavala Avalos, CR, Aguilera GE, Síndrome de Guillain Barre Crónico o Recurrente Guillain Barre Syndrome Chronic or recurrent, REVISTA MEDICA HONDURENA - VOL. 64 - No. 4 - 1996.

4. Síndrome de Guillain Barré; Francia Carolina Díaz Jaime. Integrante de la Sociedad Universitaria de Neurociencias Estudiante del 5to año Medicina BUN Synapsis Vol. 2 Abril - Junio 2007.

5. Revista de Posgrado de la Vla Cátedra de Medicina. N ${ }^{\circ} 168$ - Abril 2007 SINDROME DE GUILLAIN BARRE María Inés Acosta, María José Cañizá, Martín Fidel Romano. Dr. Ezequiel Mateo Araujo.

6. Newswanger DL. Guillain-Barré Syndrome. Am Fam Physician [online] mayo 2004; URL disponible en: http://www. aafp.org/afp/20040515/2405.html.

7. National institute of neurological disorders and stroke, Disponible en: [http:// www.ninds.nih.gov/disorders/Spani sh/el_sindrome_de_guillain_barre.htm].

8. García Ramos GS, Cacho Díaz B Síndrome de Guillain-Barré (SGB). Diag- nóstico diferencial, Rev. Mex Neuroci 2005; 6(5): 448-454

9. Puga Torres MS, Padrón Sánchez A, Bravo Pérez R. Síndrome de Guillain Barré. Rev. Cub Med Mil. [Online] abril-ju nio 2003 [fecha de acceso 15 Febrero 2017]; 32(2) URL disponible en: http:// scielo.sld.cu/scielo.php?script=sci_arttext\&pid=S0138 -6557200300020 0009\&lng=es\&nrm=iso.

10. Duarte Mote J, Díaz Meza S, Gutiérrez JR y col. Síndrome de Guillain-Barré. Acercamiento diagnóstico terapéutico. Rev. Med Int Mex. [Online] Diciembre 2005 [fecha de acceso 15 de febrero 2017]; 21 URL disponible en: http:// www.nietoeditores.com.mx/articulos. php?id_sec= 4\&id_art=1893.

11. Carbajal Ramírez A, Castañón González JA, León Gutiérrez MA y col. Plasmaféresis en el Síndrome de Guillain-Barré. Gac Méd Méx. [Online] nov/dic 2002 [fecha de acceso 10 Febrero 2017]; 138(6) URL disponible en: http://scielomx.bvs.br/scie lo.php?script=sci_arttext \&pid=S00163 $813200200060000 \overline{4} \&$ lng=es\&nrm= iso.

12. Ayres SM, Holbrook PR, Shoemarker WC, y col. Bleck TP. Trastornos neuromusculares en terapia intensiva. Tratado de Medicina Crítica y Terapia Intensiva. 3 ed. Madrid: Ed. Med Panamericana SA; 1996:15838.

13. Piferrer Ruiz E. Terapéutica en el Síndrome de Guillain-Barré. MEDISAN [online] 2000 [fecha de acceso 11 de febrero 2017]; URL disponible en: http://bvs.sld. cu/revistas/san/vol4_3_00/san10300.pdf. 